\title{
Malakoplakia of bone presenting as a pathological fracture
}

\author{
Nirmala Tyagi, Rana Sherwani, S.A. Sadiq ${ }^{1}$, Veena Maheshwari, M. Abbas ${ }^{1}$ \\ and S.P. Tyagi
}

Departments of Pathology and ${ }^{1}$ Orthopaedic Surgery, Jawaharlal Nehru Medical College, Aligarh Muslim University, Aligarh (202002), India

\begin{abstract}
Summary: A male aged 54 years presented with a pathological fracture of the right femur at the subtrochanteric level. The fracture site showed a lytic lesion with expansion of the bone, considered to be a metastasis. On histology, however, the area turned out to be malakoplakia of bone. The patient responded well to antibiotics and sulphonamides along with skeletal traction. This appears to be the fourth reported case of malakoplakia of bone.
\end{abstract}

\section{Introduction}

Malakoplakia, a lesion characterized by diffuse infiltrate of benign looking histiocytes with intracytoplasmic Michaelis-Gutmann bodies, is fairly common in the urinary ${ }^{1}$ and gastrointestinal tracts. ${ }^{2}$ Involvement of bone is extremely rare; to the best of our knowledge only three cases have been previously reported. ${ }^{3-5}$

We here report a further case of malakoplakia of bone presenting as pathological fracture.

\section{Case report}

A 54 year old man was admitted to the orthopaedic ward in July 1992 with pain in the right hip joint for 2 months. The pain increased in intensity and for the last 8 days he had been unable to walk. There was no history of trauma, fever, cough and night sweats.

On examination the right limb was abducted and externally rotated at the hip joint. There was no swelling or redness over the joint, but the area was tender. No movements were possible at the hip joint, and there was no sensory loss.

An X-ray of the right femur showed a subtrochanteric pathological fracture with lytic areas and expansion of the marrow canal (Figure 1). No other lytic areas were noticed in other bones. X-ray of chest and skull was normal.

Fine-needle aspiration from the fracture site, was inconclusive with only a few inflammatory cells and red blood cells seen. The total leucocyte count was

Correspondence: Nirmala Tyagi, M.D., B-19, Vikram Colony, Ramghat Road, Aligarh-202001 (U.P.), India. Accepted: 30 October 1993
$4.2 \times 10^{9} / 1$ with neutrophils $70 \%$. Erythrocyte sedimentation rate was $66 \mathrm{~mm}$ for the first hour (Wintrobe) and haemoglobin was $9.2 \mathrm{~g} / \mathrm{dl}$. The blood biochemistry was unremarkable.

An open biopsy was taken from the fracture site. The characteristic feature was the presence of large mononuclear phagocytes - von Hanseman cells arranged in groups or sheets separated by fibrous tissue or bony trabeculae (Figure 2). These cells had small darkly stained or vesicular nuclei with abundant eosinophilic cytoplasm, at times granular. There was intermingling of neutrophils, plasma cells and lymphocytes. Another salient feature was the presence of Michaelis-Gutmann bodies in the form of haemotoxophilic spherules within the cytoplasmic vacuoles (Figure 3 ) which were positive for iron and calcium (Figure 4). Staining with

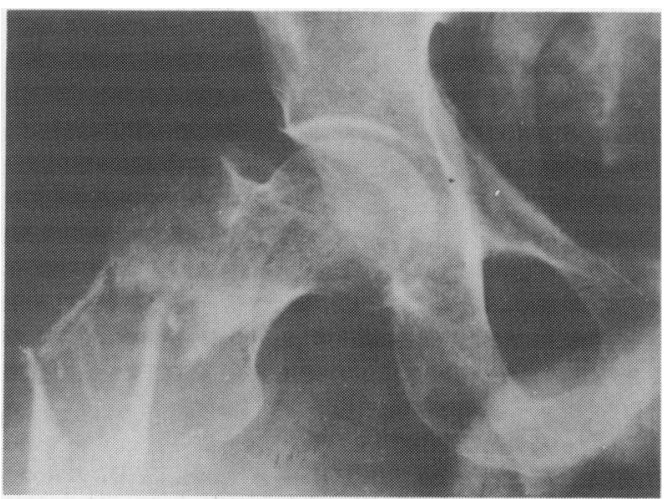

Figure 1 X-ray showing subtrochanteric fracture with lytic areas. 


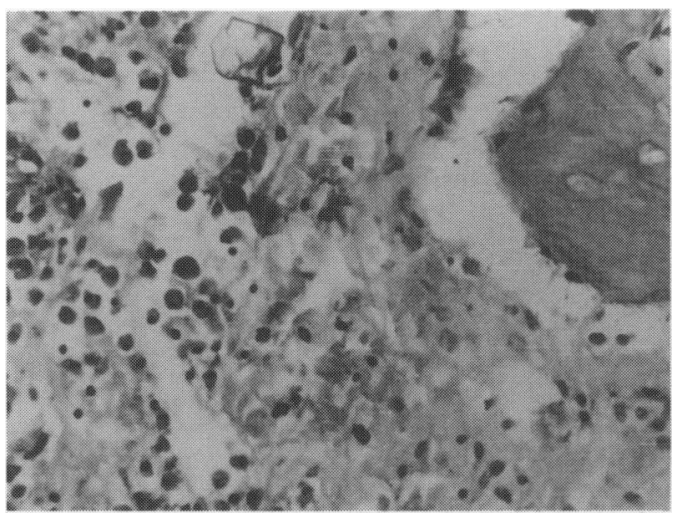

Figure 2 Cellular infiltrate comprising of histiocytes, lymphocytes and plasma cells separated by fibrous tissue and bone trabeculae. $\mathrm{H} \& \mathrm{E}, \times 200$.

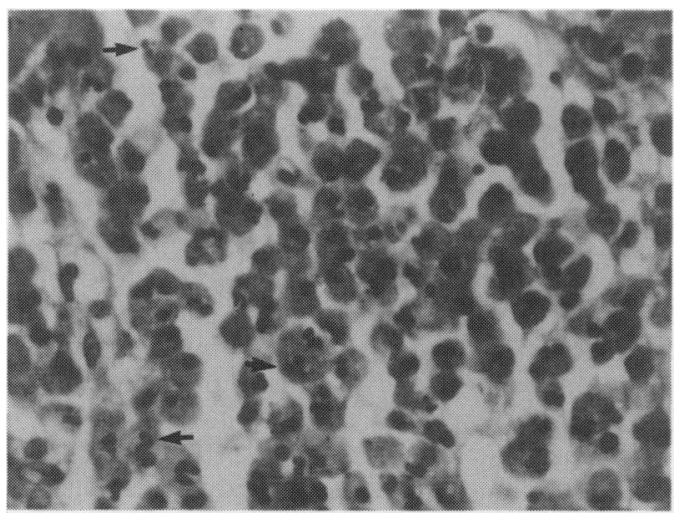

Figure 3 Diffuse infiltrate of histiocytes with the intracytoplasmic Michaelis-Gutmann bodies (arrows) in the form of calculospherules of variable size. H \& E, $\times 400$.

periodic acid-Schiff (PAS) reagent revealed PASpositive granular material inside the cytoplasm. A diagnosis of malakoplakia of bone with pathological fracture was made.

The patient was given ampicillin $250 \mathrm{mg}$ and cloxacillin $250 \mathrm{mg}$ twice daily for 2 weeks and trimethoprim $160 \mathrm{mg}$ and sulphamethoxazole $800 \mathrm{mg}$ one tablet twice daily for 1 week with

\section{References}

1. Smith, B.H. Malakoplakia of the urinary tract. Am J Clin Pathol 1965, 43: 409-417.

2. Stanton, M.J. \& Maxted, W. Malakoplakia - a study of the literature and current concepts of pathogenesis, diagnosis and treatment. J Urol 1981, 125: 139-146.

3. Gupta, R.K., Schuster, R.A. \& Cristian, W.D. Autopsy findings in a unique case of malakoplakia. A cytoimmunohistochemical study of Michaelis-Gutmann bodies. Arch Pathol 1972, 93: 42-48.

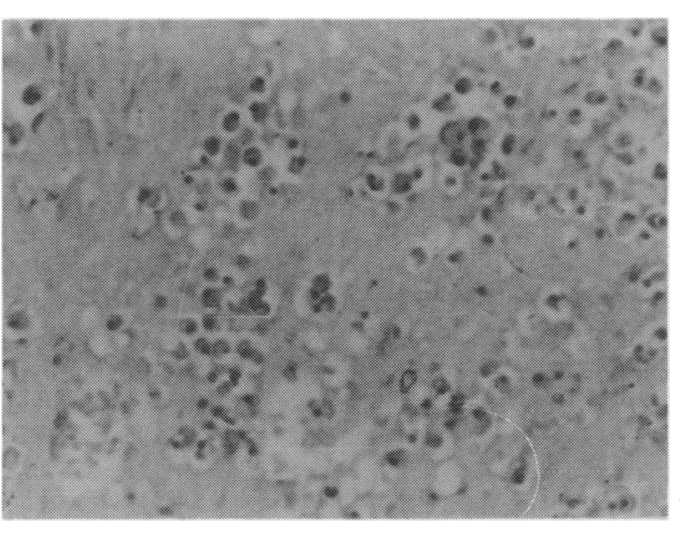

Figure 4 Michaelis-Gutmann bodies stained by the silver nitrate technique for calcium. Darkly stained rounded bodies of variable size are seen. von Kossa, $\times 200$.

skeletal traction for 6 weeks. The patient responded well and the fracture healed up clinically as well as radiologically.

\section{Discussion}

In two of the three previously published cases of malakoplakia of bone, there was a history of immunosuppressive therapy. ${ }^{4,5}$ Pathological fracture was noticed in the case reported by Weisenburger et al. ${ }^{5}$ Hence one should consider the possibility of malakoplakia of bone in cases of pathological fracture, especially in immunosuppressed patients.

Malakoplakia is now considered as a chronic inflammation and associated with coliform organisms especially Escherichia coli as Stanton and Maxted $^{2}$ have reported culture (urine, blood or from malakoplakic lesions) positive for coliform bacteria in $89 \%$ of patients, $72 \%$ of whom had $E$. coli infection. Michaelis-Gutmann bodies are the degenerated phagolysosomes with deposition of calcium and iron.,6 Hence antibiotics and sulphonamide drugs which are intracellularly active should be given ${ }^{1,2}$ as were prescribed for the present case, where microbiological studies were not done prior to treatment.

4. Van den Bout, A.H. \& Dreyer, L. Malakoplakia of bone. A case report. J Bone Joint Surg 1981, 63B: 254-256.

5. Weisenburger, D.D., Vinh, T.N. \& Levinson, B. Malakoplakia of bone - an unusual cause of pathologic fracture in an immunosuppressed patient. Clin Ortho Related Res 1985, 201: 106-110.

6. McClure, J., Cameron, C.H.S. \& Garrett, R. The ultrastructure features of malakoplakia. J Pathol 1981, 134: 13-25. 